\title{
REVIEW: A RECENT REVIEW IN APPLICATIONS OF HETEROCYCLIC COMPOUNDS AS ANTIMICROBIAL AGENT
}

\author{
MOHANAMBAL $D^{1,2}$, SRIDEVI $\mathbf{G}^{1,2}$, ARUL ANTONY $\mathbf{S}^{3}$, ANGAYARKANI $\mathbf{R}^{1}$ \\ ${ }^{1}$ Department of Chemistry, Sriram Engineering College, Perumalpattu, Chennai - 602 024, Tamil Nadu, India. ${ }^{2}$ Department of Chemistry, \\ R and D Centre, Bharathiar University, Coimbatore, Tamil Nadu, India. ${ }^{3}$ Department of Chemistry, Presidency College, Chennai - 600005 , \\ Tamil Nadu, India. Email: mohanachem2010@gmail.com \\ Received: 24 April 2018, Revised and Accepted: 09 August 2018
}

ABSTRACT

A wide development in the field of multidrug resistance in antimicrobial activity which enhance the search for development of new medicinal drugs with high potential. Schiff base heterocyclic metal complex with imine moiety, act as important antimicrobial agents due to their versatile properties such as chelation, adaptability of fine structure for a specific biological action, and chemotheraptic drugs. Schiff base compounds derived from various heterocyclic platforms have been competently reviewed.

Keywords: Ligand, Antimicrobial, Antifungal, Anticancer, Metal complex.

(C) 2018 The Authors. Published by Innovare Academic Sciences Pvt Ltd. This is an open access article under the CC BY license (http://creativecommons. org/licenses/by/4. 0/) DOI: http://dx.doi.org/10.22159/ajpcr.2018.v11i12.26890

\section{INTRODUCTION}

Schiff base metal complex, the name you heard about more than 5 decades were considered as a splendid topic in the field of research. The use of Schiff base metal complex and their progress in medical research as a fine powder of drug occupied an optimistic role in the field of pharmaceutical research. In this review article, we are discussing the on-going aspects of biological activities of metal complex such as anticancer, antifungal, antimalarial, antibacterial, antiproliferative, anti-inflammatory, and antipyretic. Apart from the biological activities of the metal complex it also shows excellent catalytic activity due to the thermal and moisture stabilities. Heterocyclic compounds possess impressive biological activity due to the strong aromaticity of the ring containing heteroatoms such as $\mathrm{O}, \mathrm{S}$, and $\mathrm{N}$. Antimicrobial resistance metamorphoses a global concern in the field of advanced multidrug research. Heterocyclic compounds used in the implementation of metal complexes as drugs to serve as remarkable medicine in the drug discovery. The pharmacological properties of heterocyclic compounds have promoted to a different level in the field of Schiff base metal complex.

The data collected from the various journals were indexed by Scopus, Pubmed, Google scholar, etc., during the past 10 years. There are more numbers of journals, but we considered that pertinent studies which have a sporting idea of the research. This review is summarized to know about the existing aspect of microbial activities of the Schiff base metal complex [1-15].

\section{APPLICATIONS OF HETEROCYCLIC COMPOUNDS AS ANTIMICROBIAL AGENT}

Heterocyclic Schiff base ligands were derived by the condensation of 3-hydroxy-methoxy benzaldehyde (iso vanillin) with furan2-carboxylic acid hydrazide and thiophene-2-carboxulic acid hydrazide. Metal complexes such as Co (II) and Cd (II) prepared with corresponding ligands. Spectroscopic methods such as Fourier transform infrared (FTIR), UV-Vis, ${ }^{1} \mathrm{H}$ and ${ }^{13} \mathrm{C}$, and magnetic measurements proved that the metal complex geometry is tetrahedral. Gram-positive bacteria and Gram-negative bacteria against metal complex and ligands proved ligands have high microbial activity [16].

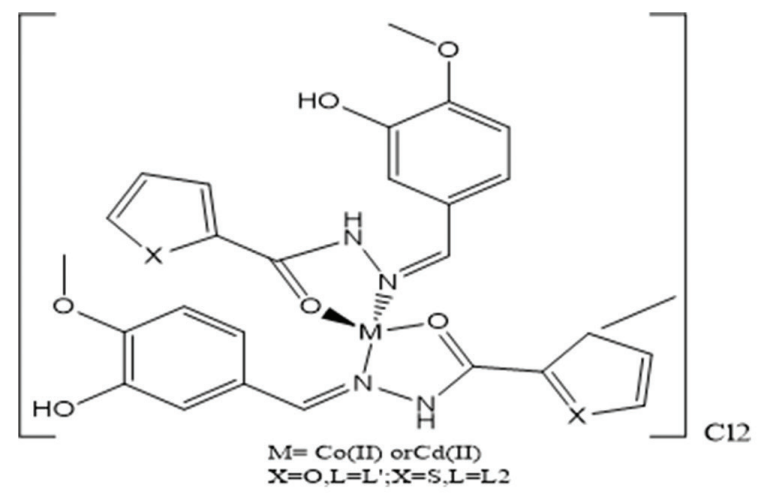

Indole-3-carboxaldehyde and m-aminobenzoic acid produce new Schiff base ligands, and their metal complexes were derived from $3^{\text {rd }}$ transition elements. They were characterized by many spectroscopic studies which are useful to prove their geometry of the molecule. The geometry reveals that Co (II) and Ni (II) are tetrahedral and Cu (II) is square planar. Disc diffusion method is taken to screen the metal complexes and their ligand with antibacterial and antifungal species. The gel-electro pores method is followed. For the nuclear activity of the ligand was assayed on CT DNA. Proposed structure of Schiff base metal complexes (a) tetrahedral geometry for $\mathrm{Co}(\mathrm{II}), \mathrm{Ni}(\mathrm{II})$, and $\mathrm{Zn}(\mathrm{II})$ complexes and (b) square planar geometry for $\mathrm{Cu}(\mathrm{II})$ complex [17].
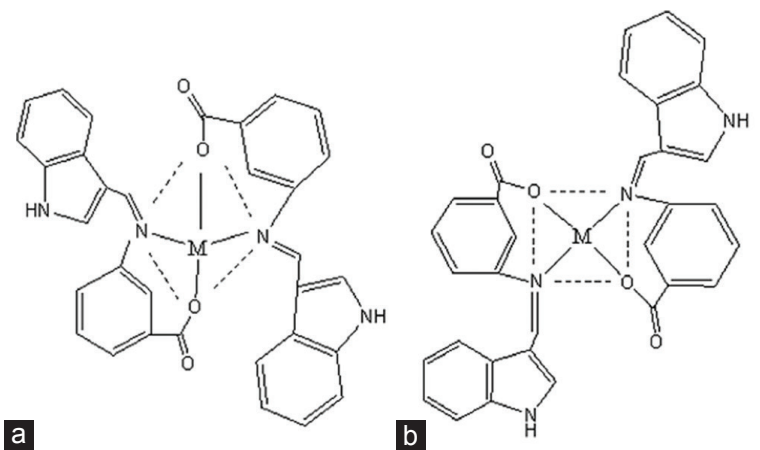
Pyrrole ring fused heterocyclic ligands were derived from indole-3carboxyaldehyde and glycylglycine (glygly). They were characterized by electronic spectra, nuclear magnetic resonance (NMR) studies, and magnetic measurements. The metal complexes are 1:1 electrolytes proved by the conductance measurement. Coordination of the metal complexes is through azomethine nitrogen, peptide nitrogen, and carboxylate oxygen atoms. The studies about the magnetic measurements revealed that the weak ferromagnetic behaviors of Co (II) and Cu (II) show paramagnetic behavior. Metal complexes coordination through water molecule can be identified by IR and thermal studies. Thermogravimetric analysis (TGA) and differential scanning calorimetry (DSC) analysis show the process of decomposition steps. The meal complex crystalline structures were derived from the X-ray diffraction (XRD) studies. The ligand and its complexes were screened by the antimicrobial activity of Kirby-Bayer disc diffusion [18].<smiles>C=C(O)CNC(=O)CN=Cc1c[nH]c2ccccc12</smiles>

A new substituted heterocyclic moiety of Schiff base ligands was prepared by the condensation of salicylaldehyde with 2-amino4-phenyl -5 methyl thiazole and their metal complexes using the transition metal such as $\mathrm{Co}(\mathrm{II}), \mathrm{Cu}(\mathrm{II}), \mathrm{Ni}$ (II), and $\mathrm{Zn}(\mathrm{II})$. All the spectroscopic studies such as FTIR, NMR, and conductance were studied for the ligands and the metal complexes. Their compounds were screened against the anticancer activity of human tumor cell MCF-7 cell, liver cancer Hep G2, lung carcinoma A549, and colorectal cancer HCT116 in comparison with the activity of doxorubicin as a reference drug and the metal complex of $\mathrm{Zn}(\mathrm{II})$ complex showed potent inhibition [19].<smiles></smiles>

The newly formed lanthanide Schiff base complex is prepared by the condensation of 2,6, diamino pyridine and anthracene - 9-carbaldehyde and they complex with lanthanide ions such as Praseodymium (Pr), Erbium (Er), and Ytterbium (Yb). FTIR data show the coordination through two Azo methane-nitrogen and the ligand act as a bidentate ligand. The metal complexes were screened against human breast cancer MCF-7 and cervical anticancer cell line which shows high resistance [20].

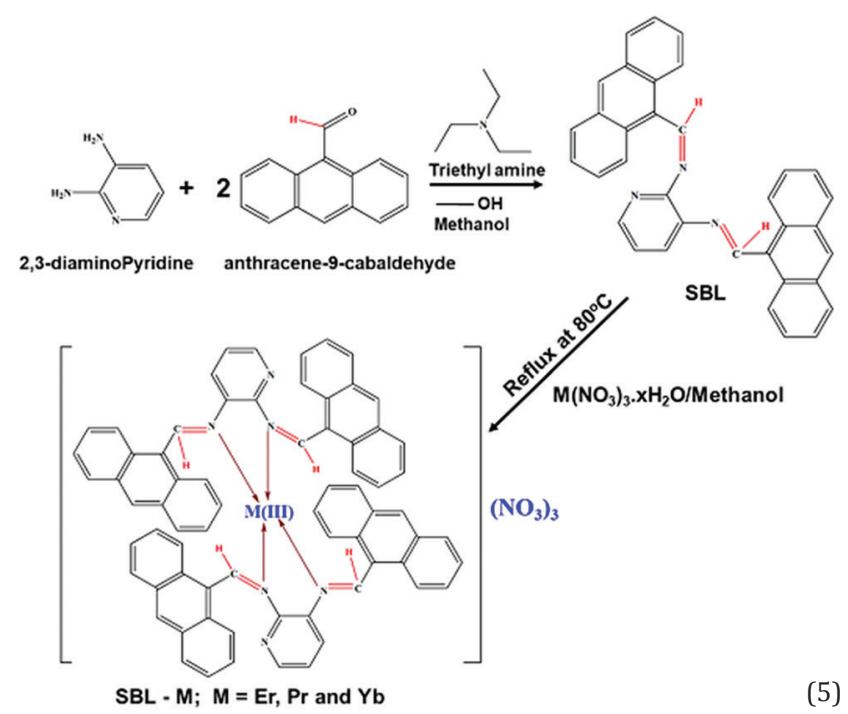

Alkaloid-containing heterocyclic Schiff base ligand 2-(2-hydroxyphenyl)3-\{[(E)-(2-hydroxyphenyl)methylidene]amino\}-2,3- dihydroquinazolin$4(1 \mathrm{H})$-one (H-HHAQ) was synthesized. The ligands with metal ions form the complexes which are studied for urease inhibitory activity. The metal ions such as $\mathrm{Cu}$ (II), $\mathrm{Co}(\mathrm{II})$, and $\mathrm{Ni}(\mathrm{II})$ showed better activities for the enzyme except for $\mathrm{Zn}$ which is inactive against the enzyme. In addition to that $\mathrm{Cu}(\mathrm{II})$ complex has greater inhibitory action [21].

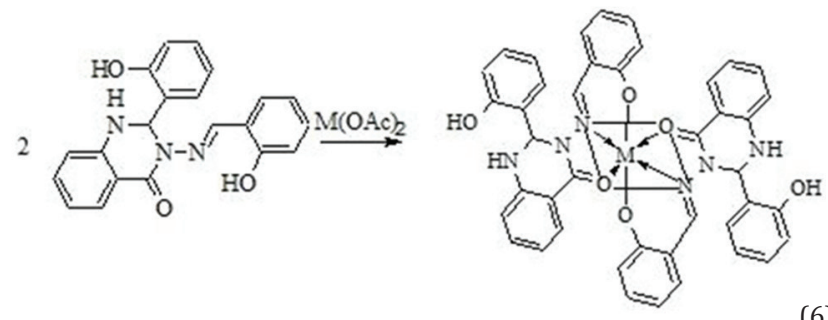

The in vitro cytotoxicity and DNA cleavage of Schiff based ligand 3-((4-phenylthiazol-2-ylimino) methyl)-2- hydroxybenzoic acid were synthesized and react with transition metal complexes such as $\mathrm{Cu}(\mathrm{II}), \mathrm{Co}(\mathrm{II}), \mathrm{Ni}(\mathrm{II}), \mathrm{Cd}(\mathrm{II})$, and $\mathrm{Zn}(\mathrm{II})$. For these complexes, elemental analysis, TG/DTA, FTIR, H-NMR, and UV-vis studies were characterized, and the data give an idea about the geometry and coordination through bidentate $\mathrm{O}-\mathrm{O}$ donar. Moreover, $\mathrm{Cu}$ (II), Co (II), and Zn (II) show an enhanced DNA cleavage activity [22].

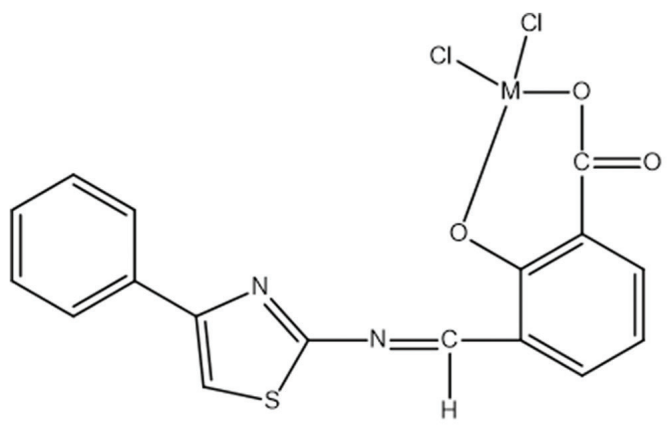

$$
\begin{aligned}
& \mathrm{M}=\mathrm{Cu}, \mathrm{Co}, \mathrm{Cd}, \mathrm{Zn}, \mathrm{And} \mathrm{Ni} \\
& \text { Proposed Structure of the complex }
\end{aligned}
$$

Benzene fused ring system has been used in the condensation of Schiff based complexes which gives new complexes with Amoxicillin trihydrate and nicotin aldehyde. Their metal complexes were characterized under spectrochemical techniques such as UV-Vis, scanning electron 
microscopy (SEM), electron paramagnetic resonance (EPR), FTIR, Mass spectroscopy, melting point, and conductivity measurements. The powder XRD pattern reveals the crystal structure of $\mathrm{Cu}$ (II) complex as a triclinic crystal system. Further tetrahedral geometry was recommended for EPR studies. Using two different concentrations the in vitro antibacterial studies were tested, and the data showed that their bacterial activity was high with the parent drug [23].

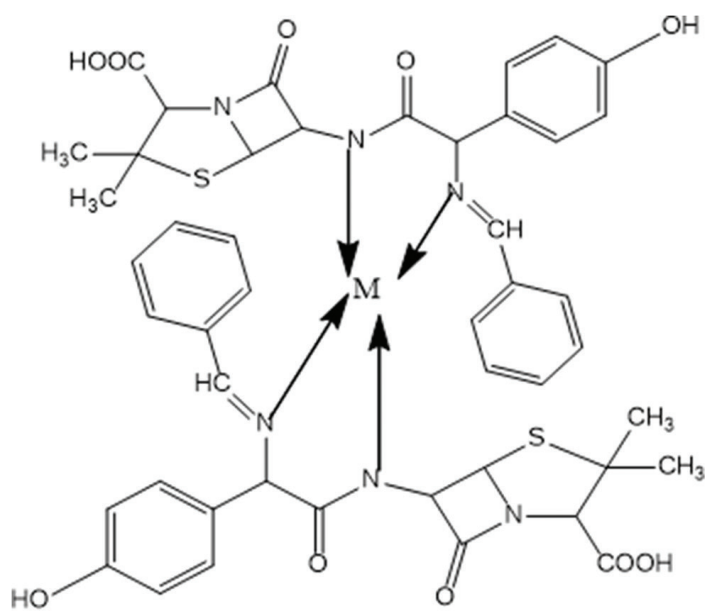

$\mathrm{M}=\mathrm{Ni}, \mathrm{Cu}, \mathrm{Zn}$

(8)

Recently reported article about the newly synthesized heterocyclic Schiff based compounds which are prepared from chalcone-3-chloro6-hydroxy-2-methyl phenyl-3-(3, 4 dimethoxy phenyl) prop-2-en-1-one with isonicotinic hydrazide in the ethanolic medium. The characterization of these compounds and their results are obtained using the techniques such as UV, Mass, FTIR, and molar conductance IR studies suggest that toward Fe(III) ligand act as a monobasic tridentate ONO donar and ON donar against VO (IV). Some more studies regarding thermal stability and decomposition of the complex are also obtained [24].

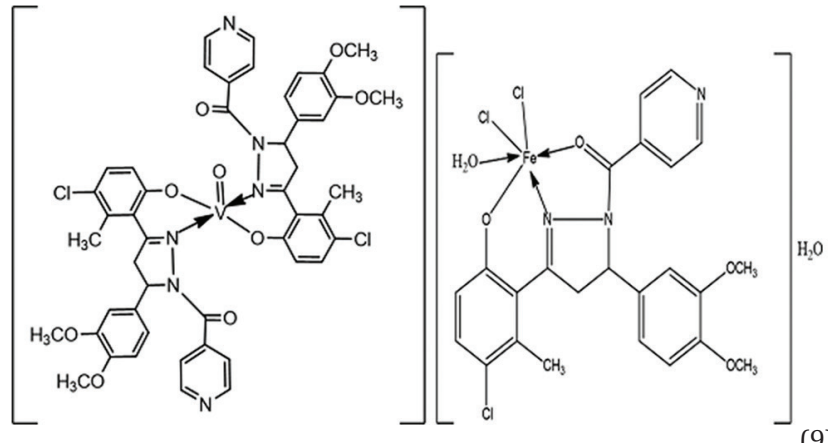

Coordination of the metal complexes plays a good role in the field of medical research. A series of tridendate Schiff base ligands are derived from the condensation of 2-hydroxyacetophenone with S-benzyldithio carbazate have been synthesized and characterized by magnetic measurements, IR, Electronic Spectra, and molar conductance, etc. The geometry of the molecule is also correlated with the biological activity. The complexes are screened and found to have high potential microbial character [25].

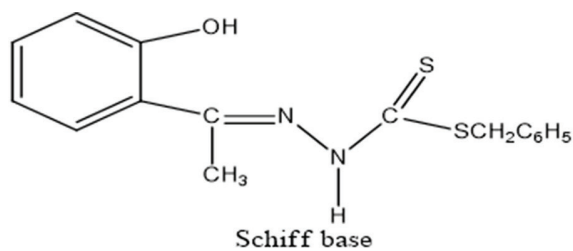

S-benzyldithiocarbazate of 2-hydroxyacteophenone
The antibacterial activity of new Schiff base ligands and their metal complexes were studied by the combination of ethylenediamine and salicylaldehyde. Using different concentration, the antibacterial activity was tested for different types of bacteria such as Pseudomonas aeruginosa, Escherichia coli, Klebsiella pneumonia, Bacillus cereus, and Salmonella typhi, and Staphylococcus aureus. Comparing the metal complexes such as $\mathrm{Cu}, \mathrm{Co}$, and $\mathrm{Ni}, \mathrm{Cu}$ showed 9.5, 9.0, and $8.0 \mathrm{~mm}$ zone of inhibition against E. coli, $S$. typhi, and $S$. aureus, and Co showed the zone of inhibition against E. coli, B. cereus, K. pneumonia, and S. aureus, in the range of 17,19 , and 22.5 . Hence, these types of complexes provide useful antibiotic drugs in the research field of medicine [26]<smiles>Oc1ccccc1/C=C/CCN[N+](O)(O)O</smiles>

Structure of Schiff base Ni complex<smiles>COc1ccccc1/C=C/CCNCN(O)O</smiles>

Structure of Schiff base Cu complex.<smiles>O=C(O)NCC/C=C/c1ccccc1OC(=O)O</smiles>

Structure of Schiff base Co complex
New Schiff base ligand has been prepared using 4-AminoAntipyrine and Thoiphene-2-carbaldehyde, and their metal complexes are prepared using the metals $\mathrm{Cu}(\mathrm{II}), \mathrm{Ni}(\mathrm{II})$, and $\mathrm{Zn}$ for which the spectroscopic studies were characterized and results give an idea about the structure of the metal complexes. The biological activity of the compound also tested with the ligands and their metal complexes [27].

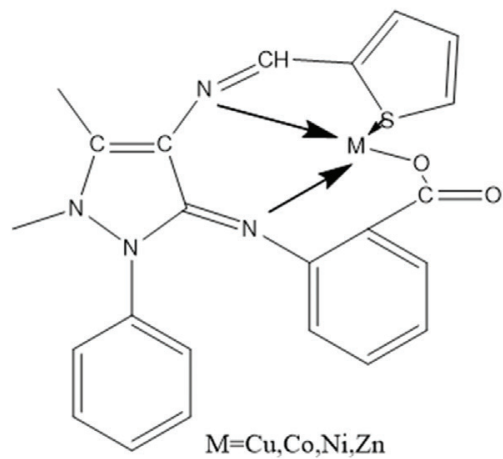

Heterocyclic compounds containing sulfur and Nitrogen of 2-aminothiazole and 8-hydroxyquinoline are mixed with Benzoinoxime to form the primary and secondary ligands. These ligands react with metal such as Co (II) and Zn (II). The metal complexes are formed in the ratio 1:2:2 with oxime as a primary ligand. The Co (II) metal complexes show distorted the octahedral geometry of mixed ligands and complexes of oxime form a square planar geometry. The mixed ligand of Zn (II) complexes shows distorted octahedral geometry and with oximes shows square planar geometry. The complexes are screened for the antimicrobial activity [28].

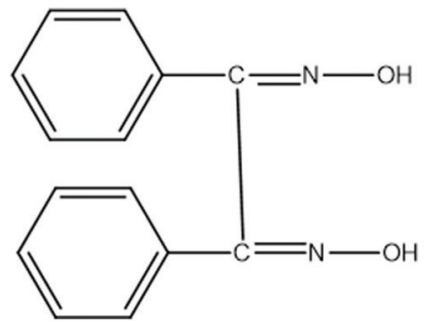


New synthesis of Zn(II) complexes using novel heterocyclic compounds have been derived from the ligands $8-[(\mathrm{Z})-\{[3-(\mathrm{N}-\mathrm{methylamino})$ propyl $]$ imino $\}$ methyl]-7-hydroxy-4-methyl-2H-chromen-2-one, 2-[(E)-\{[4(1H-1,2,4-triazol1-ylmethyl)phenyl]imino\}methyl]phenol, and (4S)-4\{4-[(E)-(2-hydroxybenzylidene)amino]benzyl\}-1,3-oxazolidin-2-one. $\mathrm{Zn}$ (II) complexes were studied by many spectroscopic techniques proposed for the structure to be Octahedral. The in vitro antimicrobial activity was a screened against Gram-negative bacteria and Grampositive bacteria and fungi such as Candida albicans and niger which showed the enhanced biological activity of Zn(II) complexes [29].<smiles>CNCCC/N=C\c1c(O)ccc2c(C)cc(=O)oc12</smiles>

1,2,4 Triazole Schiff base ligands are prepared, and their metal complexes such as $\mathrm{Cu}(\mathrm{II}), \mathrm{Cd}(\mathrm{II}), \mathrm{Sn}(\mathrm{II}), \mathrm{Zn}(\mathrm{II})$, and $\mathrm{Ni}(\mathrm{II})$ are synthesized. Physiochemical techniques have been studied for these compounds which reveal that the azomethine nitrogen and $\mathrm{S}$ atom of thiol group are responsible for coordination through metal complexes. $\mathrm{Cu}$ (II) complexes form the proposed square planar structure, and tetrahedral structure has been proposed to other metal complexes [30].

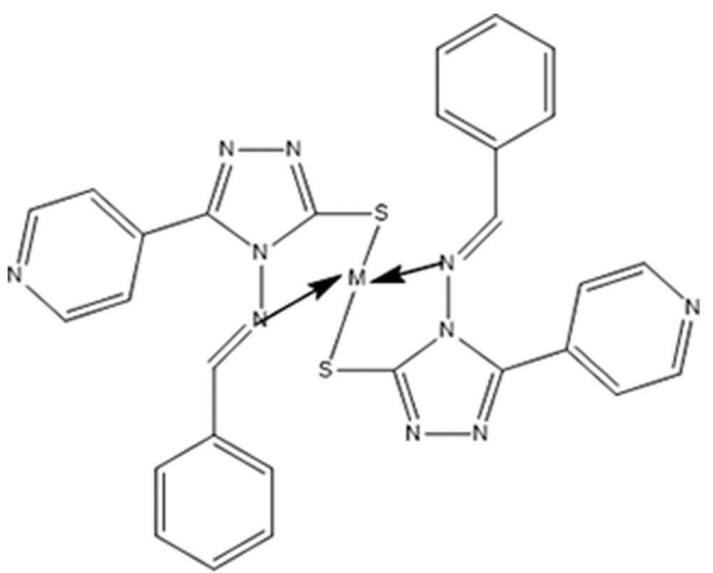

$\mathrm{M}=\mathrm{Cu}(\mathrm{II}), \mathrm{Cd}(\mathrm{II}), \mathrm{Sn}$ (II), $\mathrm{Zn}$ (II) or $\mathrm{Ni}$ (II)

New ligand containing trifunctional SNO donor system and metal II complexes were prepared using 2-acetyl thiophene benzoyl hydrazone ligand. These complexes are characteristics by various studies such as molar conductance, thermogravimetric, and magnetic moment distorted Octahedral complexes are produced in which the ligand act as SNO tridentate [31].<smiles></smiles>

Substituted Benzofuran derivatives have been synthesized, and their metal complex was characteristized by elemental analysis, magnetic moments, and conductance measurements. The elemental analysis confirms the formula ML (CL) $\mathrm{n}$ where $\mathrm{L}=\mathrm{E}-1-\mathrm{Methoxy}-\mathrm{N} 1-(2,4$, 5- trimethoxy benzylidene)benzofuran -2-carbohydrazide (L1) or (E)-N1-(2,6 dichlorobenzylidene)-7-methoxy benzofuran-2carbohydrazide L2 of the complex. The complexes were screened for their antibacterial activity. Among the metal complexes $\mathrm{Co}, \mathrm{Cu}$, and $\mathrm{Ni}$ show high activity against all microbes [32].

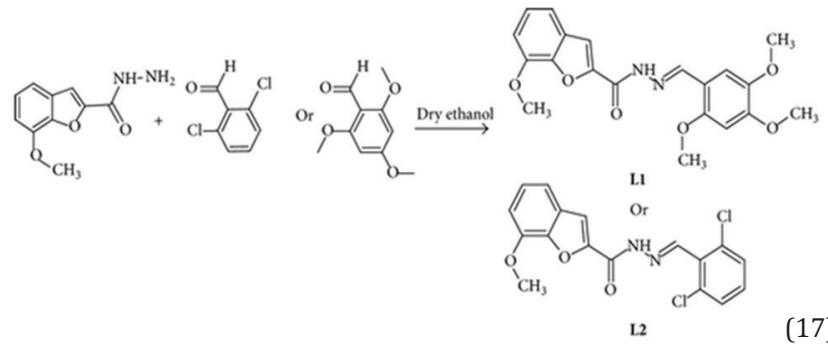

The acetylacetonate Schiff base ligand was obtained from the condensation of 4-(diethyl amino)-2-hydroxy benzaldehyde and 4 nitro benzo hydrazide or 4 methoxy-benzohydrazide. The metal complexes were prepared with Co (II), Mn(II), and Mg(II) metals. FTIR reveals the Schiff base as bidentate chelating ligands through nitrogen of azomethine and phenolic oxygen atoms. The in vitro antimicrobial screening was done against $S$. aureus and Enterococcus facials which showed the high potential activity of metal complex [33].

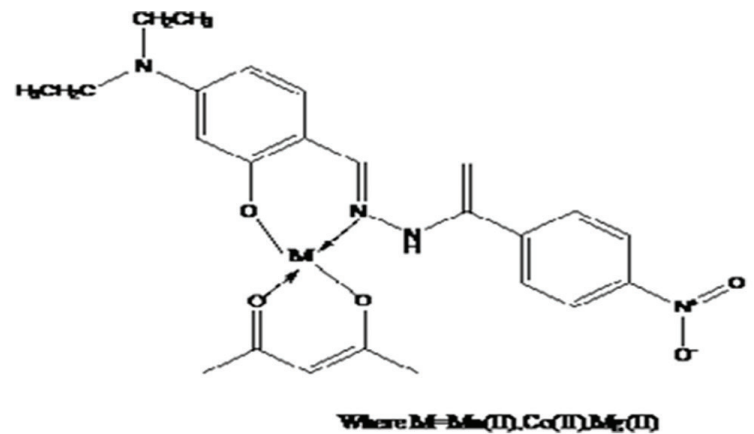

Metal complexes derived from 4-aminoantipyrine, vanillin, and $\mathrm{O}$-anisidine were prepared and synthesized. The spectroscopic techniques such as FTIR, NMR, and ${ }^{1} \mathrm{H}$ and ${ }^{13} \mathrm{C}$ NMR are analyzed and obtained the following data. Antimicrobial screening test was performed within the metal complexes. The minimum inhibitory concentration values of metal complex exhibit greater antimicrobial activity than free ligand [34].

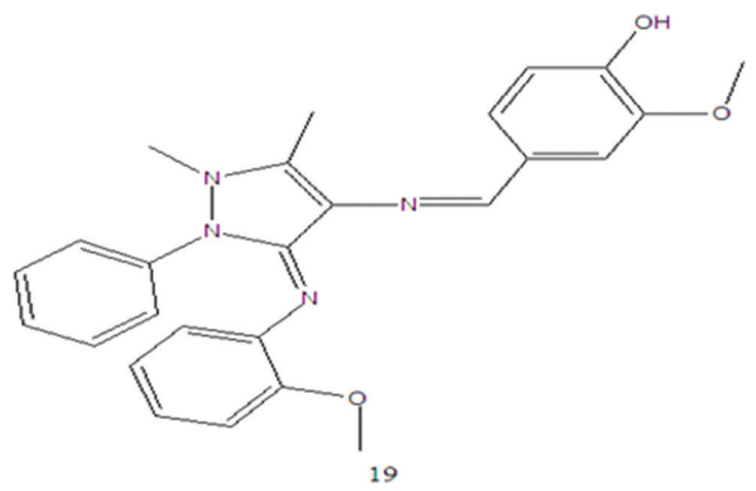

Transition metal complex derived from 2-aminomethylbenzimidazole and 4-chlorobenzaldehyde (1-(1H-benzimidazol)-2H-N-(4- chlorobenzylidene methamine) was synthesized. The spectroscopic methods such as ${ }^{1} \mathrm{H}$ and ${ }^{13} \mathrm{C}$ NMR, electron spin resonance (ESR), FTIR, UV-Vis spectra were analyzed 
for all these metal complexes which proposed an octahedral geometry to all metal complexes. The in vitro screening of antimicrobial activity was studied against two Gram-negative and Gram-positive bacteria. All the metal complexes are highly active than the ligand [35].

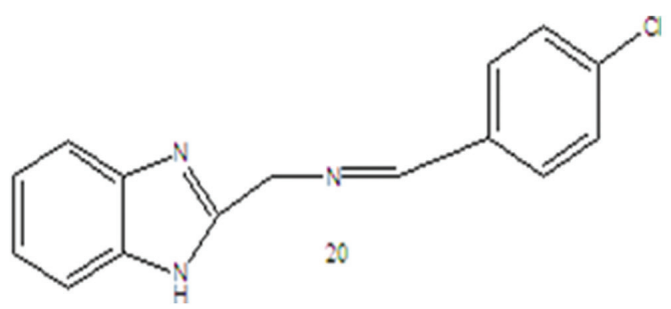

The synthesis of new benzaldehyde thiosemicarbazone-BTSCH and 3,4 dimethoxy benzaldazine-DMBA and their metal complex was prepared and screened for antibacterial activity with the five human pathogenic bacteria strains such as $S$. aureus, Bacillus subtilus, $K$. pneumonia, E. coli, and Proteus vulgaris. The concentration ranging between 0.01 and $10 \mu \mathrm{g} / \mathrm{ml}$ has a very good antibacterial activity of the metal complex [36].

New metal chelates of the type M (NQO) ${ }_{2}$ were synthesized from metals such as $\mathrm{Hg}, \mathrm{Cd}, \mathrm{Zn}$, and $\mathrm{Pb}$ where NQO-1,2 Naphthoquinone dioxime. The metal chelates were synthesized and characterized by FTIR, electronic Spectra, ${ }^{1} \mathrm{H}$ and ${ }^{13} \mathrm{C}$ NMR, DSC, and Electron Microscopy with EDAX. Square Planar structure was proposed for these metal chelates, and it is thermally stable up to $350^{\circ} \mathrm{C}$. The antimicrobial activity was screened with Gram-positive and Gram-negative bacteria and fungi with cisplatin as chemotherapeutic agent [37].

Walaah. Mohamed and et al. synthesized a new series of metal complexes derived from lornoxicam and 1, 10 phenanthroline and characterized by spectroscopic tools such as mass spectra, IR, UV-visible, ${ }^{1} \mathrm{H}$ and ${ }^{13} \mathrm{C}$ NMR, and ESR. Electrolytic nature was confirmed by the molar conductance. IR studies reveal the coordination of metal ions in a neutral bidentate manner. ESR spectra and electronic spectra assigned octahedral geometry of the ternary complexes. These complexes are screened for their antimicrobial, anticancer activity against cancer cell line. The result revealed complexes have more potent than the parent ligand [38]

Transition metal complexes of Ni (II), Zn (II), Cd (II), and Hg(II) have synthesized from dihydropyrimidine derivative of vanillin and 4-AminoAntipyrine. The complexes are characterized by UV-Vis, ${ }^{1} \mathrm{H}$, and ${ }^{13} \mathrm{C}$ NMR, which proposed the complexes have $\mathrm{ML}_{2}$ type. The tetrahedral geometry was suggested by UV-Vis and susceptibility data expects Nickel which shows a square planar complex. The in vitro antimicrobial studies were carried on these ligand and metal complexes. The metal complexes show more activity than the ligand [39].

Two metal complexes were synthesized from 2,6 bis (2-Aminophenoxymethyl)pyridine and 2,2'-bipyridine $6,6^{\prime}$-dicarboxyaldehyde in the presence of $\mathrm{Hg}(\mathrm{II})$ and $\mathrm{Cu}(\mathrm{II})$ perchlorate salts. Both compounds showed cytotoxicity on 2 cell line as a dosedependent manner. Among the complexes, the one with $\mathrm{Hg}$ (II) according to apoptotic morphology and DNA fragmentation exhibits promising potential as an anticancer compounds [40]

Unsymmetrical Schiff base ligands derived from Salicyaldehyde/5methylsalicylaldehyde and ethylene diamine or diaminomaleonitrile. They were characterized by elemental analysis and spectroscopic methods. ESR spectra showed that $\mathrm{Cu}$ (II) complexes show four lines which are a characteristic of square planar geometry. The antimicrobial activity was tested against bacteria such as $S$. aureus, Bacillus subtilus, K. Pneumonia, and also antifungal activities. The metal complexes generally show more potent than the ligand [41].

Schiff base ligands were derived from imidazole-2-carbaldehyde and glycine-glycine. The ligands react with metals such as Co (II), Cu (II), and Ni (II). Molar conductance indicates the 1:1 electrolytic nature and IR data showed that the ligand is tetradentate with imidazole nitrogen and carboxylate oxygen donar group. The SEM image shows the surface morphology of the complex. Antibacterial and antifungal studies were carried out using bacterial and fungal species which shows high for metal complex [42]

New ONO donar Schiff base ligand derived from the condensation of 5-Methyl, 3-Phenyl -1H-Indole-2-Carbohydrazide with 2-hydroxy1-naphthaldehye. The spectral analysis of the metal complex was characterized by UV-vis spectra, ESR, Thermal analysis, power XRD, and conduct metric, and magnetic susceptibility measurements. Co (II), $\mathrm{Cu}$ (II), and Ni (II) complexes have octahedral geometry and 1:2 stoichiometric ratio of the type $\mathrm{M}(\mathrm{L})_{2}$ The antimicrobial activity was screened for metal complexes and found that it possesses high potential activity [43].

A series of novel Schiff base derivatives with different substituent were screened for antibacterial activity against $S$. areus. Synthesized compounds showed a significant antibacterial activity [44].

Synthesis and biological activity of transition metal complexes containing a tetradentate $\mathrm{N}_{2} \mathrm{O}_{2}$ donor type Schiff base derived from the condensation of 4-aminoantipyrine (1-phenyl-2,3-dimethyl4-aminopyrazol5-one) with benzyl which forms stable complexes with transition metal ions such as $\mathrm{Cu}(\mathrm{II}), \mathrm{Ni}(\mathrm{II}), \mathrm{Co}(\mathrm{II}), \mathrm{Mn}(\mathrm{II}), \mathrm{Zn}(\mathrm{II})$, and $\mathrm{VO}(\mathrm{IV})$ were reported [45]. Screening results indicated that the complexes show higher antimicrobial activity than the free ligand. Such increased activity of the metal chelates can be explained on the basis of Overtone's concept [46] and the Tweedy's chelation theory [47].

The synthesized and screened for their antimicrobial Schiff base and its 3d transition metal complexes (7) of Mn(II), Fe(III), and VO (IV) derived from Ethyl 4-methyl-2-oxo-6 phenylhexahydro pyrimidine-5- carboxylate and 4-aminoantipyrine suggesting the possible use of the complexes as antibiotics [48].

The complexes of different Schiff bases (5- methyl 2-hydroxy acetophenone morpholine-Nthiohydrozone, 5-chloro2hydroxy acetophenonemorpholine-N-thiohydrazone and 5-methyl 2-hydroxy acetophenone antipyrine) with $\mathrm{Mn}$ (III) and $\mathrm{Mn}$ (II) have been synthesized [49].

Five new novel metal complex derivatives of $2 \mathrm{~N}$-salicylidene-5-( $p$-nitro phenyl)-1,3,4-thiadiazole, HL with the metal ions Vo(II), Co(II), Rh(III), Pd(II), and Au(III) have been successfully prepared in an alcoholic medium. The complexes obtained are characterized quantitatively and qualitatively using micro elemental analysis, FTIR spectroscopy, UV-Vis spectroscopy, mass spectroscopy, ${ }^{1} \mathrm{H}$ and ${ }^{13} \mathrm{C}$ NMR, magnetic susceptibility, and conductivity measurements. From the spectral study, all the complexes obtained as the monomeric structure and the metals center moieties are four-coordinated with square planar geometry except VO (II) and Co complexes which existed as a square pyramidal and tetrahedral geometry, respectively. The preliminary in vitro antibacterial screening activity revealed that complexes showed moderate activity against tested bacterial strains and slightly higher compared to the ligand, HL [50]. Coordination of biomolecules to the metal ions significantly alters the effectiveness of the biomolecules. In view of the antimicrobial activity, a series of nickel, copper, and zinc complexes of tridentate Schiff base derived from the condensation reaction of S-benzyldithiocarbazate with 2-hydroxyacetophenone have been synthesized and found to be potential antimicrobial agents. An attempt is also made to correlate the biological activities with the geometry of the complexes. The complexes have been characterized by molar conductance, magnetic susceptibility, IR, and electronic spectroscopic techniques [27]. Novel Schiff base ligand derived from 2-hydroxybenzophenone with S-benzyldithiocarbazate and its metal complexes with Ni (II), Cu (II), Zn (II), and Cd (II) have been synthesized and evaluated for their antibacterial activities by disc diffusion method 
and antifungal activities by PDA medium. The complexes have been characterized by conductance, magnetic, IR, and electronic spectroscopic techniques [51]. Transition metals such as $\mathrm{Cr}, \mathrm{Mn}$, and Fe with a Schiff base derived from 2-amino-4-ethyl-5-hydroxybenzaldehyde and thiocarbohydrazide were synthesized and characterized by several techniques, including elemental analysis (C, H, and $\mathrm{N}$ ), molar conductance measurements, magnetic measurements, and electronic, mass, and IR spectral studies. Based on these studies, a five-coordinated square pyramidal geometry for all the complexes was proposed. The Schiff base ligand and the complexes were also tested for their antimicrobial activity (against the bacteria E. coli, S. aureus, P. aeruginosa, and Bacillus megaterium, and the fungi Kluyveromyces fragilis, Rhodotorula rubra, C. albicans, and Trichoderma reesei) to assess their inhibiting potential. An attempt was also made to correlate the antimicrobial activity with the geometry of the complexes. All complexes were found to be less active against the pathogens E. coli, S. aureus, and $P$. aeruginosa. The Cr(III) complex showed the best antimicrobial activity, but the ligand alone was found to be active against the fungus $T$. reesei [52]. A new series of Copper(II), Nickel(II) Cobalt(II), and Zinc(II) complexes with two newly synthesized Schiff base ligands N-[(E)-(5Methylfuran-2-yl)methylidene]-ethane-1,2-diamine (MFMEDA) and $\mathrm{N}$-p-hydroxybenzalidine-2-aminopyridine (HBAPy) have been prepared. The Schiff bases MFMEDA and HBAPy ligands were synthesized by the condensation of 5-methyl furfural with ethylene1,2-diamine and p-hydroxybenzaldehyde with 2-aminopyridine, respectively. The ligands and their metal complexes have been characterized by FT-IR, Mass, 1 H NMR, UV-vis., elemental analysis, and Thermal gravimetric analysis. The Schiff base and their metal complexes were tested for antimicrobial activity against Gram-positive bacteria $S$. aureus and Gram-negative bacteria E. coli, S. typhi murium and fungus Aspergillus nidulence, C. albicans, and Saccharomyces cerevisiae using Broth Dilution Method [53]. Shambuling Karabasannavar and et al. synthesized that new five metal complexes with a Schiff-base ligand, 3-((4-phenylthiazol-2-ylimino) methyl)-2- hydroxybenzoic acid were synthesized with metal ions such as $\mathrm{Cu}(\mathrm{II}), \mathrm{Co}(\mathrm{II}), \mathrm{Ni}(\mathrm{II}), \mathrm{Cd}(\mathrm{II})$, and $\mathrm{Zn}(\mathrm{II})$. The reaction likely proceeds through condensation of 2-amino4-phenyl thiazole with 3-aldehydosalicylic acid and characterized by elemental analysis and various spectral studies such as FT-IR, 1H NMR, ESI mass, and TGA/TDA, and molar conductance studies. The spectral results revealed bidentate $0-0$ donor and forms the complexes having square planar geometry. The antibacterial and antifungal activity of the ligand and its metal complexes was found based on the determination of minimum inhibitory concentrations [54]. Schiff base metal complexes were prepared from 3,3'-diaminodipropylamine with different benzaldehyde derivatives. The structures of these compounds were confirmed through different spectroscopic methods such as ${ }^{1} \mathrm{H}-\mathrm{NMR},{ }^{13} \mathrm{C}-\mathrm{NMR}$, and mass spectrometry. The prepared compounds were evaluated in vitro for their antimicrobial activity against a number of pathogenic Gram-positive and Gram-negative bacteria and Candida by the two-fold serial dilution method. These compounds showed bacteriostatic rather than bactericidal activities against Gram-positive and Gram-negative bacteria. In addition, compound 3c exhibited significant anticandida activity with an MIC of $24 \mu \mathrm{g} / \mathrm{ml}$ and is, therefore, considered as a promising and potential antifungal agent; further modification can be done on the structure of the compound for a better drug candidate in the future [55]. This work was performed to synthesize various Schiff base metal complexes using cobalt, nickel, and copper followed by their antibacterial activity. Schiff bases were synthesized by the combination of Ethylene-diam in and salicyldehyde. Metal complexes of these Schiff bases were prepared from nitrate and chloride salts of $\mathrm{Ni}, \mathrm{Co}$, and $\mathrm{Cu}$ in an alcoholic medium. The chemical structures of Schiff base metal complexes were established by IR spectroscopy. The antimicrobial activities of these complexes were checked against $P$. aeruginosa, E. coli, K. pneumonia, B. cereus, S. Typhi, and $S$. aureus. Disc diffusion method was used to assess their inhibiting potential. The copper based Schiff complex displayed 9.5, 9.0, and $8.0 \mathrm{~mm}$ zone of inhibitions against E. coli, $S$. typhi, and $S$. aureus at the concentration level of $16.6 \mu \mathrm{g} / 100 \mu \mathrm{L}$. The results of the antibacterial activity of the copper complexes at the concentration of $33.2 \mu \mathrm{g} / 100 \mu \mathrm{L}$ showed $18.5,10.5$, and $10 \mathrm{~mm}$ zone of inhibitions against E. coli, S. typhi, and $S$. aureus. The nickel base complex showed no activity against the tested organisms at both concentrations. The cobalt based Schiff complex showed 17, 19,22.5, and 26.5 zones of inhibition against E. coli, B. cereus, K. pneumonia, and $S$. aureus, respectively, at16.6 $\mu \mathrm{g} / 100 \mu \mathrm{L}$ while at $33.2 \mu \mathrm{g} / 100 \mu \mathrm{L}$ this complex displayed 23.5, $30.5,26.5$, and $28.5 \mathrm{~mm}$ zone of inhibition against E. coli, B. cereus, $K$. pneumonia, and $S$. aureus. These new derivatives may provide a wide choices and flexibility for the development of new, safe, and highly active antibiotics [28]. A new Schiff base has been derived from 1,2-diacetyl benzene and 4,5-dimethyl -OPhenylenediamine and their complexes with $\mathrm{Cu}(\mathrm{II}), \mathrm{Co}(\mathrm{II})$, and $\mathrm{Ni}(\mathrm{II})$ have been synthesized and evaluated for their antibacterial activities by disc diffusion method. The complexes have been characterized by conductance, magnetic, IR, and electronic spectroscopic techniques [56]. Transition metal complexes with Schiff bases derived from 2-formylindole, salicylaldehyde, and $\mathrm{N}$-amino Rhodanine. The Schiff base ligands were characterized by elemental analysis, IR, Mass, $1 \mathrm{H}$ NMR, and electronic spectra. The free ligands and their metal complexes were also screened for antimicrobial activities against Bacillus cerens, E. coli, P. aeruginosa, S. aureus, and $C$. albicans. The results indicated that the ligands do not have any activity, where as their complexes showed more activity against the same organisms under identical experimental conditions [57]. Nickel II metal complex of Schiff base derived from benzoin and o-amino benzoic acid has been prepared and characterized by IR spectral analysis, conductance measurement, UV-visible spectral studies, and elemental analysis. The melting point of the Schiff base determined is $120^{\circ} \mathrm{C}$. The decomposition temperature of the nickel (II) complex is $155^{\circ} \mathrm{C}$, while the molar conductance value is $10.7 \mathrm{ohm}-1 \mathrm{~cm} 2 \mathrm{~mol}-1$. Antimicrobial screening of the compounds was carried out in vitro against E. coli, S. typhi (Gram-negative), and S. aureus, and Streptococcus spp. (Grampositive). The bioassay reveals a considerable activity of the Schiff base complex against the bacterial isolates [58]. The synthesis of a series of some novel Schiff base complexes of $\mathrm{Cu}(\mathrm{II}), \mathrm{Ni}(\mathrm{II}), \mathrm{Co}(\mathrm{II}), \mathrm{Mn}(\mathrm{II})$, and $\mathrm{Zn}(\mathrm{II})$ with a tetradentate Schiff base has been achieved by the reaction of malonyl hydrazide with dehydroacetic acid in ethanol under refluxing condition. All the synthesized metal complexes and ligand were characterized on the basis of elemental analysis, UV-Visible, ${ }^{1} \mathrm{H}$ and ${ }^{13} \mathrm{C}$ NMR, IR spectroscopy, and mass spectrometry. The IR spectral data suggest that azomethine $\mathrm{N}$ and enolic $\mathrm{O}$ atom are involved in coordination with metal ions, and the ligand behaves as a tetradentate ligand with ONNO donor atoms. The mass spectrum of the complexes reveals the formation of metal ligand bonding in stoichiometric ratio 1:1 (M: L). The UV-Visible data suggest the square planner geometry for the synthesized complexes. All compounds were screened for their antibacterial activity against Gram-positive and Gram-negative bacteria using ampicillin as a standard drug. It has been found that metal complexes show enhanced activity as compared to ligand, and some modification in ligand structure may lead to better antibacterial agents in future [59]. Ni(II) and Cu(II) metal complexes of simple unsymmetrical Schiff base ligands derived from salicylaldehyde/5methylsalicylaldehyde and ethylenediamine or diaminomaleonitrile (DMN) were synthesized. The ligands and their complexes were characterized by elemental analysis, ${ }^{1} \mathrm{H}$ NMR, FT IR, and mass spectroscopy. The electronic spectra of the complexes show $d-d$ transitions in the region at 450-600 $\mathrm{nm}$. Electrochemical studies of the complexes reveal that all mononuclear complexes show a one-electron quasi-reversible reduction wave in the cathodic region. ESR spectra of the mononuclear copper(II) complexes show four lines, characteristic of square-planar geometry, with nuclear hyperfine spin 3/2. The in vitro antimicrobial activity of the investigated compounds was tested against human pathogenic bacteria such as $S$. aureus, Bacillus subtilis, $K$. pneumonia, P. aeruginosa, and E. coli. The antifungal activity was tested against $C$. albicans. In general, the metal complexes have higher antimicrobial activity than the free ligands [42]. Metal complexes of $(E)$ $N$-(4-(thiophen-2-ylmethyleneamino) phenylsulfonyl) acetamide (S. $\mathrm{TH})$ Schiff bases derived from sulfacetamide ( $N$-[4-(amino-phenyl) sulfonil] acetamide) and 2-thiophenecarboxaldehyde were synthesized and characterized. Spectroscopic studies suggested that most of the 
complexes were coordinated in a regular octahedral arrangement where S.TH ligand and the central metal atom were coordinated through two $\mathrm{N}$ amino azomethine groups $(-\mathrm{HC}=\mathrm{N}-)$ and two sulfur atoms of $\mathrm{S}$ thiophene rings in $2 \mathrm{~L}: 1 \mathrm{M}$ molar ratio. Complexes have shown a promising activity on screening for the antibacterial characteristics, and antifungal (Aspergillus fumigates and C. albicans) [60]. A new Schiff base derivative ligand (LI) has been produced by condensed isatin and 2,3-diaminobutane (2:1) molar ratio. The (LI) ligand has been separated and distinguished by ${ }^{1} \mathrm{H},{ }^{13} \mathrm{C}-\mathrm{NMR}$, (CHN) elemental analysis, UV-visible, mass spectroscopy, and FTIR methods. The metal ions, cobalt(II), nickel(II), and copper(II) complexes were synthesized with the ligand. The complexes were typified by, UV-Visible, FTIR, atomic absorption, molar conductance, magnetic susceptibility, and elemental analysis (CHN) techniques. Octahedral geometry are suggested for the metal complexes based on the results of physicochemical and spectral techniques. The TLC for (LI) ligand and complexes demonstrated single spot for each, signifying their compounds purity. All these compounds were determined aligned with two classes of human pathogenic; bacteria Gram-positive and Gram-negative [61]. The synthesis and characterization of novel transition 3d metal complexes of copper (II), nickel (II), cobalt (II), and chromium (III) involving the Schiff base of melonal were explored to examine their biological activity. Characterization of the complexes was carried out using matrix-assisted laser desorption/ionization-time-of-flight, gas chromatography-mass spectrometry, TGA, UV-Visible, and IR spectrophotometry. The antimicrobial studies were conducted against six bacterial strains and six fungi. The minimum inhibition concentration observed was compared against the standard antibiotic gentamycin and the antifungal drug amphotericin. The activity studies indicated that cobalt (II) complex exhibited activity better than standard drug amphotericin against Penicillium chrysogenum. Molecular docking study confirms the protein binding and supports the experimental finding. Binuclear cobalt (II) and chromium (III) bridging complexes of Schiff base ligand were obtained [62]. Metal complexes of Mn(II), Fe(II), Co(II), and Cd(II) ions with Schiff base ligand 4- \{(pyridin-2-ylimino)methyl $\}$ phenol derived from condensation of 2-amino pyridine with 4- hydroxybenzaldehyde were prepared. The ligand and complexes were isolated from the reaction in the solid form and characterized by conductivity, magnetic moment, TLC, IR, UV-Visible, thermal analysis, and some physical measurements. During complexation reaction with transition metal ions Schiff base act as a deprotonated tridentate ligand and IR spectra showed that $\mathrm{N}$ and $\mathrm{O}$ atoms are coordinated to the central metal atom. The observed values confirmed that the complexes have octahedral geometry. The Schiff base and its metal complexes have been found to have moderate to strong antibacterial activity [63]. The transition metals with the Schiff bases, formed by condensation of 2-Hydroxy-1- naphthaldehyde/Salicylaldehyde and p-Anisidine with Neutral bidentate ligand 4-Hydroxybenzldehyde/3-Ethoxy-4hydroxybenzaldehyde (Ethylevanilline) and o-Phenylinediamine have been synthesized and characterized. All prepared compounds were also evaluated for their antibacterial and antifungal activities by the agar well diffusion method. The antibacterial activity was tested against the bacteria B. subtilis (Gram-positive), E. coli (Gram-negative). The antifungal activity was tested against $A$. niger. The standard Streptomycin has been evaluated with the results obtained for antibacterial and antifungal activities [64]. Schiff base ligand derived from 2-amino 4,6 dihydroxypyrimidine and P- chlorobenzaldehyde has been reported and the ligand was treated with $\mathrm{Cu}, \mathrm{Ni}$, and $\mathrm{Co}$ to obtained the following metal complexes. The ligand and its complexes were screened for their antifungal and antibacterial activity against A. niger, P. chrysogenum, Fusarium moneliforme and Aspergllus flavus and E. coli, S. typhi, S. aureus, and B. subtilis. The result indicated that the complexes exhibited good antifungal and antibacterial activities [65]. The synthesized ligands, along with its metal complexes were screened for their in vitro antibacterial activity against four bacterial pathogens (E. coli, B. subtilis, S. aureus, and Proteus vulgareous). A novel Schiff base metal complexes were synthesized and well characterized by elemental analyses and spectral studies. Physical and analytical data suggest that the Schiff base acts as tridentate ligand toward metal ions through
azomethine-N, deprotonated-O of 2-aminophenol, and $\mathrm{O}$-atom of furan moiety. The results of these studies revealed that the free ligand and its metal complexes showed significant antibacterial potency [66]. All the newly synthesized compounds were screened for their antimicrobial activity. For antibacterial activity, we used $S$. aureus microbial type culture collection (MTCC 96) and Streptococcus pyogenes (MTCC 443) as Gram-positive, E. coli (MTCC 442) and P. aeruginosa (MTCC 441) as Gram-negative strains using ampicillin, chloramphenicol, and ciprofloxacin as a standard antibacterial drug. Antifungal activity was screened for three different fungal spices C. albicans (MTCC 227), A. niger (MTCC 282), and Aspergillus clavatus (MTCC 1323). Griseofulvin and nystatin used as a standard antifungal drug. Majority of the compounds exhibited good antibacterial, antifungal, and antituberculosis activity [67].

\section{CONCLUSION}

Schiff base explored versatile antimicrobial activity in the research field. Moreover, metal on complex formation, their in vitro antimicrobial activity has increased more when compared to ligands. This review will create new ideas in the field of medicine which helps the scientist to produce more new drugs which are specific in action. In spite of various syntheses in the drug analysis there is still a need to explore new drugs which are useful for future generation.

\section{AUTHOR'S CONTRIBUTIONS}

Corresponding author has reviewed all the research article about antimicrobial activity of Schiff base metal complexes.

\section{CONFLICTS OF INTEREST}

Authors declare that they have no conflicts of interest.

\section{REFERENCES}

1. Al Mulla A. A review: Biological importance of heterocyclic compounds. Pharm Chem 2017;9:141-7.

2. Borad MA, Bhoi MN, Prajapati NP, Patel HD. Review of synthesis of multispiro heterocyclic compounds from isatin. Int $\mathrm{J}$ Rapid Commun Synth Org Chem 2013;43:1057.

3. Sönmez M, Şekerci M. A new heterocyclic schiff base and its metal complexes. Synth Reactivity Inorg Metal-Organic Chem 2010;34:489-502.

4. Kajal A, Bala S, Kamboj S, Sharma N, Saini V. Schiff bases: A versatile pharmacophore. J Catalysts 2013;2013:Article ID: 893512, 14.

5. Tobriya SK. Biological applications of schiff base and its metal complexes-a review. Int J Sci Res (IJSR) 2014;3:1254-6.

6. Tadele KT. Antioxidant activity of Schiff bases and their metal complexes: A recent review. J Pharm Med Res 2017;3:73-7.

7. Parasha RK, Sharma RC, Govind M. Biological activity of some schiff bases and their metal complexes. Biol Trace Elem Res 1989;23:145-50.

8. Bernadette SC, Brian D, Denise A, Egana KK, Georgina R. Anticancer and antifungal activity of copper (II) complexes of quinolin-2(1H)-onederived schiff bases. Inorg Chim Acta 2010;363:4048-58.

9. Singh WM, Dash BC. Synthesis of some new Schiff bases containing thiazole and oxazole nuclei and their fungicidal activity. Pesticides 1988;22:33-7.

10. Shaikh AA, Raghuwanshi MG, Khurshid I, Molvi K, Nazim S, Ahmed A. Schiff's bases and amides of selected five membered heterocyclic compounds: A review. J Chem Pharm Res 2013;5:14-25.

11. Spinu C, Pleniceanu M, Cristian T. Biologically active transition metal chelates with a 2-thiophenecarboxaldehyde derived Schiff base: Synthesis, characterization, and antibacterial properties. Turk J Chem 2008;32:487-93.

12. Mehmet G, Mehmet S, Ismet B. Synthesis, characterization, and antimicrobial activity of a new pyrimidine schiff base and its $\mathrm{Cu}(\mathrm{II}), \mathrm{Ni}(\mathrm{II}), \mathrm{Co}(\mathrm{II}), \mathrm{Pt}(\mathrm{II})$, and $\mathrm{Pd}(\mathrm{II})$ complexes. Turk J Chem 2012;36:189-200.

13. Pratibha MS, Vatsala P, Uma V. Biologically active Co (II), Ni (II), Cu (II) and $\mathrm{MN}(\mathrm{II})$ complexes of schiff bases derived from vinyl aniline and heterocyclic aldehydes. Int J Chem Technol Res 2009;1:225-32.

14. Nazk MA, Shaalanand ND, Sahar S. Synthesis, spectroscopic, thermodynamic and biological activity studies of Schiff base and metal complexes derived from 2-[1h-pyrrol-2-ylimino methyl]-5-phenyl- 
1,3,4-oxadiazole. Glob J Sci Front Res B Chem 2015;15:14-8

15. Asif NK, Ajay P, Sharad T, Jagannath JK, Lokhande MV. Antibacterial activity of 2-[(2-chloro-4-methylbenzylidene) amino] pyridin-4-ol and its some transitional metal ion complexes. IOSR J Appl Chem 2014; 7:14-20

16. Abhishek K, Fernandes J, Pankaj K. Synthesis, antimicrobial and antiinflammatory studies of some novel schiff base derivatives. Int J Drug Dev Res 2014;6:165-7.

17. Ahmed RM, Yousif EI, Al-Jeboori MJ. Co(II) and Cd(II) complexes derived from heterocyclic schiff-bases: Synthesis, structural characterization, and biological activity, Hindawi publishing corporation. Sci World J 2013;2013:Article ID: 754868, 6.

18. Nair MS, Arish D, Joseyphus RS. Synthesis, characterization, antifungal, antibacterial and DNA cleavage studies of some heterocyclic Schiff base metal complexes. J Saudi Chem Soc 2012;16:83-8.

19. Joseyphus RS, Nair MS. Synthesis, characterization and biological studies of some $\mathrm{Co}$ (II), $\mathrm{Ni}$ (II) and $\mathrm{Cu}$ (II) complexes derived from indole-3-carboxaldehyde and glycylglycine as schiff base ligand. Arabian J Chem 2010;3:195-204

20. Abd-Elzaher MM, Labib AA, Mousa HA, Moustafa SA, Ali MM, ElRashedy AA. Synthesis, anticancer activity and molecular docking study of Schiff base complexes containing thiazole moiety, Beni-Suef university. J Basic Appl Sci 2016;5:85-96.

21. Andiappan K, Sanmugam A, Deivanayagam E, Karuppasamy K, Kim HS, Vikraman D, et al. In vitro cytotoxicity activity of novel schiff base ligand-lanthanide complexes. Sci Rep 2018;8:3054.

22. Ikram M, Rehman S, Subhan F, Akhtar MN, Sinnokrot MO. Synthesis, characterization, thermal degradation and urease inhibitory studies of the new hydrazide based schiff base ligand 2-(2-hydroxyphenyl)-3- $\{[(\mathrm{E})-$ (2-hydroxyphenyl) methylidene] amino $\}-2,3$ - dihydroquinazolin4(1H)-one. Open Chem 2017; 15:308-19.

23. Karabasannavar S, Allolli P, Shaikh IN, Kalshetty MB. Synthesis, characterization and antimicrobial activity of some metal complexes derived from thiazole schiff bases with in-vitro cytotoxicity and DNA cleavage studies. Indian J Pharm Educ Res 2017;51:490-501.

24. Chaudhary NK, Mishra P. Metal complexes of a novel schiff base based on penicillin: Characterization, molecular modeling, and antibacterial activity study Hindawi. Bioinorg Chem Appl 2017;2017:Article ID: 6927675,13

25. Thakare AP, Mandlik PR. Synthesis, spectroscopic and thermal studies of $\mathrm{Fe}(\mathrm{III})$ and VO (IV) complexes of heterocyclic schiff base ligand. Indian J Adv Chem Sci 2017;5:318-23.

26. Nasrin D, Alam MA, Hossain MN, Nazimuddin M. Synthesis, characterization and antimicrobial activity of metal complexes of schiff's base derived from S-benzyldithiocarbazate with 2-hydroxyacetophenone. Chem J 2013;3:13-9.

27. Sheheryar,ParveenZ,Rahman T, Zeb mMA,

Z RehmanW Synthesisand antibacterial activity basemetal complees. Int J Biosci 2017;10:259-64.

28. Selvi ET, Mahalakshmi S. Synthesis and characterization of heterocyclic schiff base ligand derived from 4-aminiantipyrine and thiophene-2carbaldehyde. Int J Adv Res Dev 2017;2:51-6.

29. Joshi SR, Habib SI. Co (II) and Zn (II) metal complexes of heterocyclic schiff bases: A synthesis, spectral and antimicrobial study. Orient J Chem 2014;30:1343-13.

30. Yamgar RS, Nivid Y, Nalawade S, Mandewale M, Atram RG, Sawant SS, et al. Novel zinc(II) complexes of heterocyclic ligands as antimicrobial agents: Synthesis, characterisation, and antimicrobial studies. Bioinorg Chem Appl 2014;2014:276598.

31. Hasan A, Ameer A, Ahmed A, Yousif E. Synthesis and characterization of some transition metal (II) complexes with 1,2,4-triazole schiff base. J Chem Pharm Res 2015;7:531-5

32. Saadeh SM. Synthesis, characterization and biological properties of $\mathrm{Co}(\mathrm{II}), \mathrm{Ni}(\mathrm{II}), \mathrm{Cu}$ (II) and $\mathrm{Zn}$ (II) complexes with an SNO functionalized ligand. Arabia J Chem 2013;6:191-6.

33. Dikio CW, Ejidike IP, Mtunzi FM, Klink MJ, Dikio ED. Hydrazide schiff bases of acetylacetonate metal Complexes: Synthesis, spectroscopic and biological studies. Int J Pharm Pharm Sci 2017;257-67.

34. Manjula B, Antony SA, Dhanaraj CJ. Synthesis, spectral characterization, and antimicrobial activities of schiff base complexes derived from 4-aminoantipyrine. Spectrosc Lett 2014;47:1-9.

35. Jogi P, Padmaja M, Kumar KP, Gyanakumari C. Studies on DNA cleavage and antimicrobial screening of transition metal complexes of a schiff base derived from 2-(aminomethyl)-benzimidazole and p-chloro benzaldehyde. J Chem Pharm Res 2012;4:1389-97.

36. DawoodZF,Al-Bustani RR, Taha M. Biological activity of the complexes of $\mathrm{Hg}(\mathrm{II}), \mathrm{Zn}(\mathrm{II})$ and $\mathrm{Cd}(\mathrm{II})$ mixed ligands (thiosemicarbazone and azine) Part II. Natl J Chem 2009;36:760-8.

37. Gonewar NR, Jadhav VB, Jadhav KD, Sakure SS, Killedar AA, Sarawadekar RG. Synthesis, characterisation and antimicrobial activity of bivalent metal $(\mathrm{Zn}, \mathrm{Cd}, \mathrm{Hg}, \mathrm{Pb}$ and $\mathrm{Ag}$ ) chelates of 1 , 2- naphthoquinone dioxime. IOSR J Pharm 2012;2:25-33.

38. Mahmoud HW, Mohamed GG, El-Dessouky MM. Synthesis, characterization and in vitro biological activity of mixed transition metal complexes of lornoxicam with 1, 10-phenanthroline. Int $\mathrm{J}$ Electrochem Sci 2014;9:1415-38

39. Mangaiyarkkarasi P, Arulantony S. DNA cleavage, cytotoxic activities, and antimicrobial studies of some novel schiff base transition metal complexes derived from 4-aminoantipyrine and dihydropyrimidone of vanillin. Int J Curr Pharm Res 2016;8:43-7.

40. Ergene E, Sivas H, Benkl K. Biological activities of $\mathrm{Cu}$ (II) and $\mathrm{Hg}$ (II) complexes of a heptadentate schiff base ligand. Turk J Biol 2010;34:379-387.

41. Rajasekar M, Sreedaran S, Prabhu R, Narayanan V, Jagadeesh R. Synthesis characterization and antimicrobial activities of $\mathrm{Ni}$ (ii) and $\mathrm{cu}$ (ii) schiff base complexes. J Coord Chem 2010;63:136-46.

42. Joseyphus RS. Nayar MS. Synthesis characterization and antimicrobial activities of transition metal complex with the schiff base derived from imidazole-2-carbazaldehyde and glycylglycine. J Coord Chem 2008;62:319-327.

43. Gunvanthrao YN, Mathada MB. Metal (ii) complexes of ono donor schiff base ligand as a new class of bioactive compounds containing indole core: Synthesis and characterization. Int J Pharm Pharm Sci 2015;8:197-204.

44. Xia ZL, Yi L, Hua CL, Jun HY, Jun Y, Zhi HP. Inhibitory study of some novel schif base derivaties on Staphylococcus areus by micaroclarometry. Thermochim Acta 2006;440:51-6.

45. Raman N, Kulandaisamy A, Jeyasubramanian K. Synthesis, spectral, redox, and antimicrobial activity of schiff base transition metal (ii) complexes derived from 4-aminoantipyrine and benzyl. Synth React Inorg Metal Organic Chem 2002;32:1583-610.

46. Dharmaraj N, Viswanathamurthi P, Natarajan K. Ruthenium (ii) complexes containing bidentate schiff bases and their antifungal activity. Trans Met Chem 2001;26:105-9.

47. Anjaneyula Y, Rao RP. Preparation, characterization and antimicrobial activity studies on some ternary complexes of $\mathrm{Cu}$ (ii) with acetylacetone and various salicylic acids. Synth React Inorg Met Org Chem 1986;16:257-72.

48. Mohanambal D, Antony SA. Synthesis, characterization and antimicrobial activity of some novel schiff base $3 \mathrm{~d}$ transition metal complexes derived from dihydropyrimidinone and 4-aminoantipyrine. Res J Chem Sci 2014;4:11-17.

49. Nizami G, Gargand P, Ahmad S. Synthesis, characterisation and structural studies of complexes containing different schiff bases with $\mathrm{mn}(111)$ and $\mathrm{mn}$ (ii) transition metals. Orient J Chem 2013;29:1579-84.

50. Yousif E, Majeed A, Al-ammarrae K, Salih N, Salimon J, Abdullah B. Metal complexes of schiffbase:Preparation, characterization and antibacterial activity. Arabia J Chem 2017;10:1639-44.

51.Nasrin D, Alam MA, Hossain MN, Nazimuddin M. Synthesis, characterization and antimicrobial activity of metal complexes of schiff's base derived from s-benzyl dithio carbazate with 2-hydroxyacetophenone. Chem J 2013;3:13-9

52. Nasrin D, Alam MA, Rahman IM, Banu H, Nazimuddin M. Synthesis, characterization and antimicrobial activity of some metal complexes with schiff base containing $\mathrm{o}, \mathrm{n}$ and $\mathrm{s}$ as the donor atoms. Int J App Nat Sci 2013;2:1-8.

53. Kumar G, Kumar D, Singh CP, Kumar A, Rana VB. Synthesis, physical characterization and antimicrobial activity of trivalent metal schiff base complexes. J Serb Chem Soc 2010;75:629-37.

54. Sikarwar P, Tomar S, Singh AP. Synthesis, spectral characterization and antimicrobial activity of schiff bases and their mixed ligand metal complexes of co (ii), ni (ii), cu (ii) and zn (ii). Am J Chem 2016;6:119-25

55. Matar SA, Talib WH, Mustafa MS, Mubarak MS, Al Damen MA. Synthesis, characterization, and antimicrobial activity of Schiff bases derived from benzaldehydes and 3,3'-diaminodipropylamine.Arabia $\mathrm{J}$ Chem 2015;8:850-7.

56. Kumari E, Singh SK. Synthesis, characterisation and antimicrobial activity of some schiff base metal chelates. J Chem Pharm Res 2017;9:180-4

57. Elzahany EA, Hegab KH, Khalil SK, Youssef KN. Synthesis, characterization and biological activity of some transition metal complexes with schiff bases derived from 2-formylindole, salicyladehyde, and n-amino rhodanine. Aust J Basic App Sci 
2008;2:210.

58. Muhammad AS, Shedewo OA, Bayero. Sythesis, characterization and antibacterial properties of nickel (ii) schiff base complex derived from benzoin and oamino benzoic acid. J Pure App Sci 2015;8:33-6.

59. Saini RP, Kumar V, Gupta AK. Synthesis, characterization, and antibacterial activity of a novel heterocyclic schiff's base and its metal complexes of first transition series. Med Chem Res 2014;23:690-8.

60. Abu-Khadra AS, Afify AS, Mohamed A, Farag RS, Hassan Y, Enein A. Preparation, characterization and antimicrobial activity of schiff base of (e)- $n$ - (4-(thiophen-2-ylmethyleneamino) phenylsulfonyl) acetamide metal complexes. Open Bioact Comp J 2018;6:1-10.

61. Waddai FY, KareemEK, Hussain SA. Synthesis, spectral characterization and antimicrobial activity of some transition metal complexes with new schiff base ligand (BDABI). Orient J Chem 2018;34:434-43.

62. Sridhar G, Bilal MI, Easwaramoorthy D, Rani SK, Kumar BS, Manoha CS. Synthesis, characterization and antimicrobial activities of copper, nickel, cobalt, chromium complexes derived from (z)-4-fluoro$n$-(2,7-dimethylhept-6-enylidene) benzenamine. J Braz Chem Soc
2017;28:756-67.

63. Hossain MS, Zakaria CM, Zahan MK. Synthesis and characterization with antimicrobial activity studies on some transition metal complexes of n, o donor novel schiff base ligand. J Sci Res 2017;9:209-18

64. Patel KN, Patel SG, Thakor YJ, Bhatt VD, Srivastava SS, Synthesis, characterization and antimicrobial activity of some transition metal complexes of Schiff base and neutral bidentate ligand. Inorg Chem Indian J 2012;7:16-24.

65. Sakhare DT, Chondhekar TK, Shankarwar SG, Shankarwar AG. Synthesis, characterization of some transition metal complexes of bidentate schiff base and their antifungal and antimicrobial studies. Ad App Sci Res 2015;6:10-6.

66. Chaudhary NK. In vitro antibacterial studies of some transition metal complexes of schiff base derived from 2-aminophenol and furan-2carbaldehyd. Arch App Sci Res 2013;5:227-31.

67. Soni HI, Patel NB. Pyrimidine incorporated schiff base of isoniazid with their synthesis, characterization and in vitro biological evaluation. Asian J Pharm Clin Res 2017;10:209-14. 